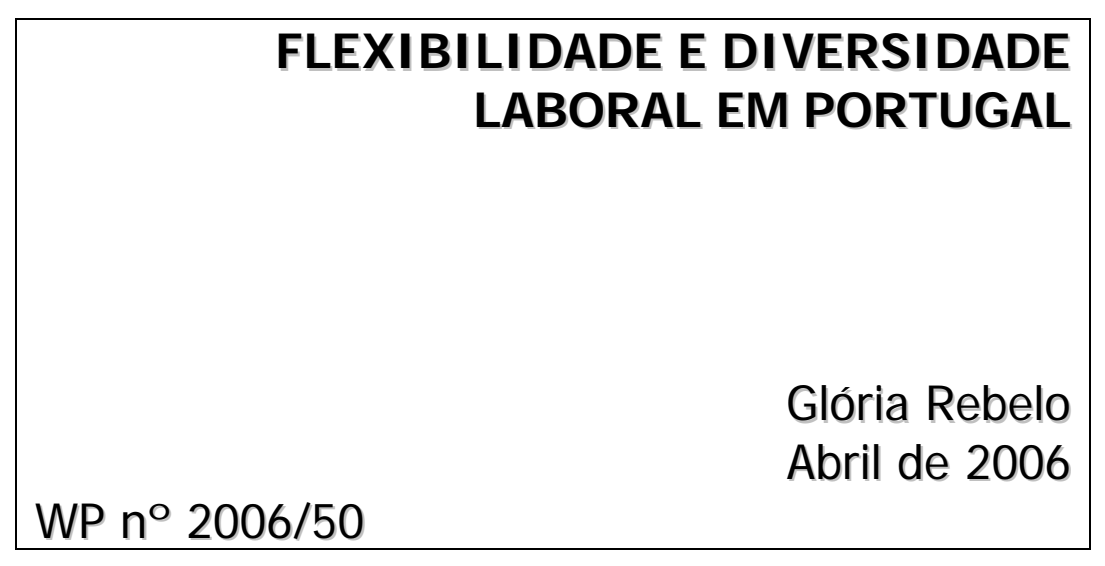

DOCUMENTO DE TRABALHO

WORKI NG PAPER 


\title{
FLEXIBILIDADE E DIVERSIDADE LABORAL EM PORTUGAL
}

\author{
Glória Rebelo ${ }^{1}$ \\ (gloria.rebelo@netcabo.pt)
}

WP n $2006 / 50$

Abril de 2006

Abstract

1. Introdução: flexibilidade e competitividade 2

2. Da diversidade contratual no actual Código do Trabalho 5

2.1. 0 contrato de trabalho a termo 5

2.2. 0 contrato de trabalho temporário 8

2.3. 0 contrato de trabalho a tempo parcial 10

2.4. 0 contrato de teletrabalho $\quad 14$

3. 0 contrato de prestação de serviços e o trabalho independente 18

4. Flexibilidade e mobilidade 19

5. Considerações finais 21

Bibliografia

\footnotetext{
${ }^{1}$ Doutora pelo ISEG-UTL e Mestre pela Faculdade de Direito da Universidade de Lisboa. Investigadora do Dinâmia - Centro de Estudos Sobre a Mudança Socioeconómica.
} 


\section{$\underline{\text { Resumo: }}$}

A subida do desemprego e a necessidade das empresas aumentarem a sua competitividade, têm conferido em Portugal - à semelhança do que tem vindo a acontecer noutros países - uma importante dimensão ao debate sobre a flexibilização, em particular ao tema da flexibilização da lei laboral.

Tendo por base a emergência do Código do Trabalho (Lei nº 99/2003, de 27 de Agosto) neste working paper apresentamos uma reflexão acerca da recente evolução da lei laboral no mercado de trabalho português. De facto, desde 2003, que o Código do Trabalho sistematiza e flexibiliza a legislação portuguesa, facultando às empresas numerosos meios para desenvolver uma gestão de recursos humanos flexível. Assim - e partindo da consagração de diversas propostas legais - reflectiremos sobre a possibilidade de as empresas portuguesas disporem de sobrecapacidades para fazer face a um imprevisto, ligadas não só aos produtos e aos processos mas, e sobretudo, à gestão dos recursos humanos. Realçaremos que a capacidade de adaptação empresarial a mudanças não antecipadas passa não só por formas de flexibilidade utilizadas numa óptica quantitativa (que implicam o recurso, por exemplo, despedimentos) mas igualmente por uma acção de planeamento estratégico e antecipado da gestão das pessoas, aplicada ao serviço de estratégias de flexibilidade qualitativas (maxime através do recurso a formas flexíveis de contratação e/ou de medidas de flexibilidade assentes na mobilidade).

\section{Abstract:}

The rise of unemployment and the need to increase firms competitiveness have conferred in Portugal - as it has come to happen in other countries - an important dimension to the labour flexibility debate, mainly on the subject of labour law flexibility.

Based on the Labour Code (Law n ${ }^{\circ}$ 99/2003, of August, 27th) in this working paper we discuss the recent evolution of the labour law in the Portuguese labour market. In fact, since 2003 the Labour Code systematizes and increases flexibility in the Portuguese labour law, giving to the firms numerous ways to develop a flexible human resources management. Thus - and after focusing on diverse legal proposals - we will discuss the possibility of the Portuguese firms to make use of their over-capabilities to face the unexpected. These concern not only the products and processes but also the human resources management practices. We will point that the firms ability to anticipate changes includes the use of quantitative flexibility (that entails, for example, dismissal) and also strategic human resources planning applied as qualitative flexibility (maxime through flexible contract forms and/or mobility measures). 


\section{Introdução: flexibilidade e competitividade}

O tema da flexibilização da lei laboral tem vindo a ocupar algum espaço na reflexão socioeconómica e jurídica da sociedade portuguesa.

No sentido de reagir à crise económica dos anos 1970 (que enfraqueceu substancialmente o modelo fordista), as décadas de 1980 e 1990 pautaram-se pela adopção progressiva de medidas de flexibilidade laboral, encaradas como um dos mais importantes - senão o mais importante - motores de desenvolvimento produtivo das empresas, quer na sua ligação às políticas de gestão dos recursos humanos, quer às políticas de produção.

À semelhança do que tem vindo a acontecer noutros países, em Portugal a subida do desemprego, a par da vontade das empresas de reduzirem os seus custos e de aumentarem os seus lucros, têm conferido a este debate uma importante dimensão: no quadro dos novos sistemas de produção e das concepções modernas em matéria de gestão, repensa-se o funcionamento do mercado de trabalho e da organização do trabalho sob a égide da ideia da flexibilidade.

Na verdade, as empresas enfrentam necessidades de modificações súbitas, que por vezes exigem respostas muito rápidas e processos de mudança onde se implemente simultaneamente o muito simples e o muito complexo. Deste modo, muitas empresas procuram formas de trabalho flexíveis atendendo ao seu desejo de responder com maior facilidade a estes desafios. E se para as empresas se trata, geralmente, de reduzir os custos de trabalho (principalmente por razões de concorrência), o conceito de flexibilidade possui um conteúdo muito mais amplo e múltiplo, compreendendo, nomeadamente, quer a multiplicação de formas de contratação laboral; quer as vicissitudes próprias da relação individual de trabalho (que passam pela variação dos horários de trabalho, pela repartição flexível do trabalho, pela mobilidade funcional, pela mobilidade geográfica) e até pela multiplicidade de formas de cessação do contrato de trabalho.

Em Portugal, e como é sabido, desde início da década de 1990 que tem procurado flexibilizar a lei laboral. Após a aprovação da Lei ${ }^{0}$ 64-A/89, de 27-02, que procurou flexibilizar o regime dos despedimentos (compensando essa flexibilidade com a limitação do recurso à contratação por tempo determinado), passando pela aprovação da Lei n 21/96, de 17-01, que consagrou a flexibilização do tempo de trabalho, e em particular a redução dos períodos normais de trabalho, pela lei que regulou o regime jurídico do trabalho a tempo parcial (Lei $\mathrm{n}^{\circ}$ 103/99, de 26-07), até ao actual Código do Trabalho, o legislador tem proposto uma série de incentivos quer à dinamização de novas formas de contratação laboral, quer à mobilidade funcional e geográfica da nossa força-de-trabalho.

Ora, é precisamente acerca desta vontade de flexibilizar o mercado de trabalho português, através de diversos tipos de contratação laboral, que deixamos aqui algumas reflexões.

E tendo como pano de fundo objectivos macroeconómicos tais como o reforço da competitividade, a promoção da produtividade, ou o aumento da colaboração entre parceiros sociais, há muito que os empregadores portugueses reclamavam a alteração do conjunto da legislação laboral 
no sentido de, nomeadamente, ser revisto o regime de adaptabilidade do tempo de trabalho, de ser considerado o alargamento da possibilidade de recurso a contratos a termo e a enunciação genérica dos motivos que possibilitam este tipo de contrato; de viabilizar a possibilidade de não reintegração em caso de despedimento ilícito; ou introduzir maior dinâmica na contratação colectiva (maxime através de regras que façam caducar automaticamente as Convenções Colectivas de Trabalho e/ou do afastamento de normas imperativas legais pela negociação colectiva).

Recorde-se que o compromisso dos Estados-membros da UE para as políticas nacionais de Emprego assenta na ideia de que cada Estado têm ainda um papel activo na criação de emprego, identificando que empregos querem criar e que empregos é possível criar. Além disso, como se sabe, no seio dos países membros da UE permanece - ao nível da própria concepção de lei do trabalho - o debate clássico que opõe as visões ditas 'neoliberais’ e as mais ‘socializantes': as primeiras colocam o acento tónico no funcionamento do mercado, as outras na acção reguladora ou mesmo voluntarista do Estado. Assim o movimento de flexibilização da Lei do Trabalho assume múltiplas formas nos diferentes países e que as manifestações em cada país reflectem as diferenças entre os ordenamentos jurídicos, as ideologias políticas que suportam essa flexibilidade e os respectivos sistemas de relações profissionais. Associada à temática da flexibilidade das formas contratuais - e muitas vezes objecto de análise concomitante - encontra-se a temática da precariedade laboral ${ }^{2}$. Num recente relatório da OCDE (OECD Observer, 2003) conclui-se que "ao nível da organização do trabalho - e mesmo nos países onde a tradição liberal é mais antiga (v.g., EUA e Reino Unido) - a mudança proporcionada pelo movimento de aumento da precariedade da actividade laboral apresenta-se como um fenómeno novo para as pessoas habituadas a um regime de segurança material de base”.

No seu conjunto o Código do Trabalho (CT) - Lei nº 99/2003, de 27-08 - além de sistematizar a legislação laboral portuguesa, flexibiliza-a. Se por flexibilidade podemos entender a ideia da "capacidade de adaptação das organizações às mudanças impostas pelas circunstâncias exteriores que condicionam a sua actividade” (Pinto, 1996: 137), o actual Código é um instrumento que possibilita - em pleno - às empresas essas adaptações (em termos de produção e os métodos de organização e gestão) às alterações ocorridas no mercado em que actuam ${ }^{3}$.

A flexibilidade implica (re)organização do trabalho, e os seus efeitos sobre a competitividade dos produtos (condição indispensável para a remodelação da actividade económica) são inúmeros. Daí a importância de medidas de gestão antecipadoras das alterações tecnológicas e das necessidades dos clientes ou mercado (Rebelo, 2002c: 20-23).

\footnotetext{
${ }^{2}$ Temática por nós já amplamente abordada em Rebelo, G. (2002a), Emprego e formas de precariedade da actividade laboral - o caso de Portugal no contexto da UE, tese de doutoramento, ISEG/UTL, Lisboa. Sobre este tópico temático veja-se com interesse o recente artigo de Godinot, X. e Richou, S. (2003), "La pauvreté en Europe: essai de prospective: quatre scénarios sur la précarité et la grande pauvreté en Europe à l'horizon 2015, Revue Futuribles, 290, pp. 33-48.

${ }^{3}$ Diferente de flexibilidade é a desregulamentação laboral, termo usado para designar a eliminação das regras legais que definem as condições de trabalho ou a sua substituição por disposições de convenções colectivas de trabalho ou por cláusulas dos contratos de trabalho, tendo em vista alcançar uma maior flexibilidade (Pinto, 1996: 111).
} 
Partilhamos a opinião de Monteiro Fernandes quando defende que não existe verdadeiramente uma relação de incompatibilidade radical entre Direito do Trabalho e competitividade (Monteiro Fernandes, 2002: 66) ${ }^{4}$. O Direito laboral português inspira-se em dois princípios básicos que são comuns à generalidade dos ordenamentos jurídicos da União Europeia (UE): de um lado, o princípio da liberdade de desvinculação, que é inerente às relações jurídicas duradouras constituídas por tempo indeterminado; do outro, o princípio da estabilidade, também ele comum a muitas relações duradouras, mas que assume uma importância decisiva no contrato de trabalho.

Sabemos que os contratos de trabalho de duração determinada (v.g., a termo e temporários), a tempo parcial e/ou de teletrabalho, se tornaram uma das características essenciais do mercado de trabalho europeu, deixando de ser considerados como uma excepção à lei e tornando-se "de facto" a norma. Por toda a Europa, diversas disposições legais organizam o trabalho em torno destes novos esquemas contratuais, conferindo aos empregadores a possibilidade de escolher livremente entre a contratação de duração indeterminada e a contratação determinada ou, entre a contratação a tempo inteiro e contratação a tempo parcial (Rebelo, 2001b). Neste sentido, o actual Código do Trabalho vem reforçar - alargando a tipologia contratual e flexibilizando os próprios requisitos de contratação - a possibilidade dos empregadores recorrerem, no seio da organização empresarial a diversas formas de contratação paralelas à contratação por tempo indeterminado, permitindo ao empregador o recurso a importantes instrumentos de gestão flexível.

\section{Da diversidade contratual no actual Código do Trabalho}

Assim, nos próximos quatro pontos propomos uma análise de quatro formas contratuais consideradas ainda pelo legislador de carácter excepcional no plano contratual - que, de certa forma, espelham o movimento de flexibilização da legislação laboral em Portugal.

\subsection{O contrato de trabalho a termo}

Constituindo uma forma de contratação subordinada de duração determinada, os contratos de trabalho a termo (certo ou incerto) são aqueles em que o termo (isto é o seu fim) é fixado desde a sua negociação. O termo poderá ser certo ou incerto, consoante se trate - respectivamente - de fixar expressamente uma determinada duração ao contrato ou, de forma diferente, de prever que o contrato durará o tempo necessário para executar certa tarefa ou actividade.

Os contratos a termo correspondem, assim, a situações em que a contratação é feita por uma duração dada, certa ou incerta, e em que no fim desse período o trabalhador termina o seu contrato.

\footnotetext{
${ }^{4}$ Não obstante, e também na linha do que afirma Monteiro Fernandes, cremos que "não é à reforma do Direito do Trabalho que convém dar prioridade, mas sim à própria noção de competitividade” (Monteiro Fernandes, 2002: 67).
} 
Em qualquer destes "sub-tipos” contratuais a duração da relação laboral - ao contrário da regra no Direito do Trabalho - é, à altura da formalização do contrato, previamente indicada mediante aposição de um termo resolutivo ao contrato de trabalho.

Nascida na generalidade dos países europeus no decurso da década de 1950 como uma forma marginal de emprego, o recurso ao trabalho a termo acentuou-se a partir de meados da década de 1970, apresentando-se actualmente como uma forma flexível de emprego dominante. Este tipo de contrato designa um trabalho por natureza provisório e não um trabalho intermitente ou um trabalho à peça.

Com a sua consagração legal a lei portuguesa quis realçar o carácter excepcional da figura afirmando, por exemplo, no preâmbulo do DL n 64-A/89, de 27-02 - diploma que congregou o regime dos contratos de trabalho a termo certo e a termo incerto - que "a amplitude da contratação passa a restringir-se a situações rigorosamente tipificadas”, estabelecendo para isso uma lista exaustiva de justificações para a celebração dos contratos a termo (motivos de contratação tipificados).

Recentemente o Código do Trabalho alterou parcialmente o regime do contrato a termo, designadamente, no que respeita aos períodos máximos de contratação (e subsequentes renovações) e ainda aos motivos de contratação.

Se até à entrada em vigor do Código do Trabalho - ou seja até 1 de Dezembro de 2003 - a duração máxima dos contratos a termo certo era 36 meses no limite de duas renovações (nos termos do disposto no $n^{\circ} 2$ do art. $44^{\circ}$ do DL no 64-A/89, de 27-02), com o Código o legislador consagrou a possibilidade de - mantendo-se a regra da renovação contratual por duas vezes, até 3 anos - permitir ao empregador proceder a mais uma renovação (no limite são possíveis agora 3 renovações) até 6 anos (n ${ }^{\circ} 1$ e $n^{\circ} 2$ do art. $\left.139 \mathrm{CT}\right)^{5}$. Já os contratos a termo incerto - por natureza e na linha do já disposto no agora revogado DL $\mathrm{n}^{\circ}$ 64-A/89, de 27-02 - duram por "todo o tempo necessário à substituição do trabalhador ausente ou à conclusão da actividade cuja execução o justifique, não estando, portanto sujeitos a períodos mínimos ou máximos de duração” (art. 144º CT).

Além disso, e como já o afirmámos, no contexto do que há muito vinha sendo reclamado pelos empregadores portugueses, foi alargada a possibilidade de recurso a contratos a termo através da enunciação dos motivos que possibilitam este tipo de contrato. Assim, o actual Código do Trabalho permite a admissão a termo em situações de substituição indirecta do trabalhador (nos termos do disposto nas al. a), b) e c) do art. $129^{\circ} \mathrm{CT}$ ) e permite também a admissão a termo de trabalhador que ocupe o posto de trabalho de trabalhador a tempo completo que tenha, temporariamente, passado a prestar trabalho a tempo parcial (nos termos da al. d) do art. $129^{\circ} \mathrm{CT}$ ).

\footnotetext{
${ }^{5}$ Excepcionalmente, prevê-se o limite dos dois anos de duração máxima para as situações de lançamento de nova actividade de duração incerta, de início de laboração de uma empresa, ou de trabalhadores desempregados de longa duração, e o limite de 18 meses para a contratação de trabalhadores à procura de primeiro emprego (nos termos do disposto no $\mathrm{n}^{\circ} 3$ do art. $139^{\circ} \mathrm{CT}$ ).
} 
Na perspectiva do empregador, o objectivo do recurso a este tipo de contratos é, acima de tudo, o de retardar, tanto quanto possível, a passagem a contratos indeterminados, a fim de prolongar ao máximo a "experimentação" do candidato, produzindo assim um autêntico "viveiro" de entre os quais se escolherão os melhores para uma contratação definitiva (Rebelo, 2003: 99). Representando aos "olhos da lei" uma modalidade excepcional de emprego que visa cobrir necessidades empresariais a um período limitado - pois recorde-se a regra contratual continua a ser a da contratação por tempo indeterminado - o recurso ao contrato a termo constitui actualmente uma etapa “quase obrigatória” do processo de inserção nos “empregos típicos” (Rebelo, 2003: 99).

Não obstante, na prática muitas empresas recorrem a este tipo contratual para, de forma “quase permanente”, obviarem às suas necessidades de mão-de-obra. A Lei nº 18/2001, de 3-07, havia expressamente coarctado a possibilidade legal de os empregadores poderem contratar sucessivamente trabalhadores a termo para o mesmo posto de trabalho, e o Código do Trabalho estabelece agora a possibilidade de "contratar para o mesmo posto de trabalho sucessivamente a termo" nos casos previstos no $\mathrm{n}^{\circ} 2$ do art. $132^{\circ} \mathrm{CT}$, a saber: "nova ausência de trabalhador substituído, quando o contrato de trabalho a termo tenha sido celebrado para a sua substituição (al. a)); acréscimos excepcionais da actividade da empresa, após a cessação do contrato (b)); actividades sazonais (al. c)); trabalhador anteriormente contratado ao do regime aplicável à contratação de trabalhadores à procura de primeiro emprego (al. d))”.

Se traduzindo uma fonte de flexibilidade quantitativa, a sucessão no tempo de contratos deste tipo permite ajustar o recurso 'trabalho' às necessidades empresariais - sem incorrer nos custos elevados de uma ruptura contratual, sobretudo de serviços onde a actividade é sazonal como a hotelaria-restauração e o comércio - ela apresenta, por outro lado, numerosos inconvenientes, em particular a provisoriedade do vínculo entre empregado subordinado e a empresa, com repercussões ao nível da aprendizagem, da formação profissional e da partilha de competências (Almeida, P. P. e Rebelo, G., 2004b: pp. 37-45).

Enquanto, para alguns, os contratos a termo constituem uma forma de emprego que permite contornar as prescrições da lei contra o despedimento sem justa causa (Rudolph, 2000: 240), para outros trata-se de uma figura excepcional na lei, que utilizada de forma regular poderá ter incidências nefastas a nível do tecido social (Kovács, 1998: 99). Acresce que este fenómeno, comum à generalidade das formas de emprego precárias, agrava-se porque nestas circunstâncias para além do poder normal de direcção do empregador acresce o poder deste de dar seguimento ou não à relação de trabalho, acentuando o grau de instabilidade desta relação.

\section{Quadro sinopse - Contrato de trabalho a termo}

\begin{tabular}{|c|c|c|c|}
\hline & Anterior Lei & Código do Trabalho \\
& & $\begin{array}{c}\text { - Regime do Decreto- Lei } \\
\mathbf{n}^{\circ} \text { 64-A/89, de 27-02 }\end{array}$ & $\begin{array}{c}\text { - Regime da Lei no 99/2003, de 27- } \\
08\end{array}$ \\
\hline
\end{tabular}




\begin{tabular}{|c|c|c|c|}
\hline & & (LCCT) & \\
\hline $\begin{array}{c}\text { Contrato } \\
\text { a termo }\end{array}$ & $\begin{array}{l}\text { Admissibilidade do } \\
\text { termo }\end{array}$ & 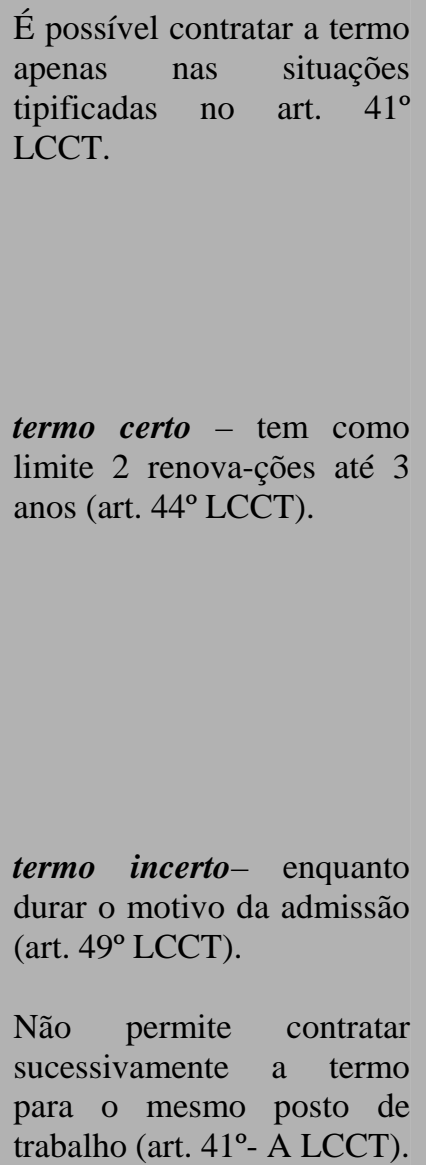 & $\begin{array}{l}\text { Permite a admissão a termo nas } \\
\text { situações já tipificadas na anterior lei } \\
\text { bem como nas situações de } \\
\text { substituição indirecta de trabalhador } \\
\text { nos termos do disposto nas al. a), b) e } \\
\text { c) do art. } 129^{\circ} \text { e, ainda, do art. } 143^{\circ} \text {. } \\
\text { termo certo - tem como limite } 2 \\
\text { renovações até } 3 \text { anos e ainda a } \\
\text { possibilidade de uma terceira } \\
\text { renovação até ao limite máximo } \\
\text { temporal de } 6 \text { anos (n } 1 \text { e }{ }^{\circ} 2 \text { do } \\
\text { art. } 139^{\circ} \text { ). Excepcionalmente } \\
\text { estabelece-se a duração máxima } \\
\text { contratual de } 24 \text { meses ou de } 18 \\
\text { meses para situações previstas no } n^{\circ} \\
3 \text { do art. } 139^{\circ} \text {. } \\
\text { termo incerto - mantém-se a regra e } \\
\text { dura enquanto durar o motivo da } \\
\text { admissão (art. } 144^{\circ} \text { ). } \\
\text { Em certas situações permite contratar } \\
\text { sucessivamente para o mesmo posto } \\
\text { de trabalho a termo ( }{ }^{\circ} 2 \text { do art. } 32^{\circ} \text { ). }\end{array}$ \\
\hline
\end{tabular}

\section{2. $O$ contrato de trabalho temporário}

Outra forma de trabalho assalariado de duração limitada que detalhamos neste ponto é o trabalho temporário, cuja progressão e evolução da regulamentação acompanham de alguma forma a normalização do contrato dito “tradicional”.

A designação desta realidade nem sempre é consensual e pode mesmo diferir de região (e/ou país) para região. Por exemplo, a nível internacional a designação "trabalho temporário" é muitas vezes utilizada numa acepção ampla, abrangendo qualquer forma de trabalho de duração limitada ${ }^{6}$.

Segundo a OCDE, o trabalho temporário é "a situação em que uma empresa cede a título oneroso e por tempo limitado a outra empresa, a disponibilidade da força de trabalho de certo número de trabalhadores, que ficam funcionalmente integrados na organização da empresa utilizadora”.

Trata-se de uma situação de prestação de trabalho que comporta uma relação jurídica triangular, tendo como partes o empregador temporário, o trabalhador temporário e a empresa utilizadora. Esta relação assenta na existência de dois contratos autónomos no plano jurídico mas interdependentes no ponto de vista funcional. Após a celebração de um contrato de trabalho

\footnotetext{
${ }^{6}$ Nomeadamente o Eurostat na sua publicação intitulada UE Labour Force Survey. 
temporário entre a empresa de trabalho temporário (ETT) e o trabalhador, outro contrato (de utilização do trabalho temporário) é estipulado entre a ETT e a empresa-cliente (utilizador). Nesta relação contratual triangular a ETT cede à empresa utilizadora os trabalhadores que previamente se comprometeram a trabalhar para a empresa utilizadora sob sua autoridade e direcção. O trabalho temporário opera então uma "partilha do estatuto de empregador pela ETT e pelo utilizador" (Lobo Xavier, 1999: 152): a ETT contrata, remunera e exerce poder disciplinar; a empresa utilizadora exerce sobre o trabalhador os poderes de autoridade e direcção próprios da entidade empregadora. Na empresa utilizadora, os trabalhadores estão sujeitos ao poder disciplinar da empresa de trabalho temporário e, ainda, a algumas regras jurídicas que caracterizam a relação jurídica assalariada, nomeadamente relativas à higiene saúde e segurança no trabalho e à duração do trabalho (Rebelo, 2003: 101).

O recurso à contratação através de trabalho temporário é relativamente recente. Com este tipo de contratação as empresas de trabalho temporário procuram, de forma temporária, colocar à disposição de utilizadores trabalhadores que elas mesmas contratam e remuneram. Desde a década de 1950 que as grandes empresas portuguesas recorrem ao trabalho temporário por necessidades muito circunstanciais. Contudo é a partir dos anos de 1980, que o crescimento do trabalho temporário se difunde e generaliza em termos de sectores de actividade económica e tipos/dimensão de empresas. Como referem Baker e Christensen, hodiernamente observa-se uma mudança complexa ao nível do tipo de contratações, das relações entre empregados e empregadores, e das funções exercidas nas organizações (v.g., muitas têm sido objecto de outsoursing), podendo o controlo que a empresa exerce sobre estes trabalhadores variar significativamente (Barker e Christensen, 1998: 4).

Associada à lógica do outsourcing, este tipo de contratação alcança também o segmento das PME: muitas das contratações efectuadas em PME são feitas mediante contratos a curto prazo (alguns convertidos em contratos de duração indeterminada, após um período de avaliação), tratando-se, em suma, de mais um exemplo de contratação baseada na lógica de incerteza que caracteriza a maioria dos modos de gestão actuais ${ }^{7}$.

Em Portugal, o quadro legal do trabalho temporário foi definido em 1989 pelo DL nº $358 / 89$, de $17-10^{8}$, que veio preencher um vazio legislativo e precisar os casos de recurso a esta forma de actividade laboral, limitando abusos. Com o Código do Trabalho - e uma vez que a matéria que regula a celebração dos contratos de trabalho temporários e os contratos de utilização de trabalho temporário (art. $1^{\circ}$ a $25^{\circ}$ do DL nº 358/89, de 17-10) não foi absorvida pelo Código do Trabalho - o período máximo de utilização de um trabalhador temporário numa só empresa mantém-se inalterado:

\footnotetext{
${ }^{7}$ Por exemplo, um estudo levado a cabo pela UE em 1995, revelou que as novas PME subcontratantes da indústria automóvel, contabilizam cerca de 25\% de assalariados em contratos temporários (cfr. Arnelle, G. e René, M. (1995), Recrutement et production au plus juste - les nouvelles usines d'equipement automobile en France, CEE, Dossier $n^{\circ} 7$, Bruxelas).

${ }^{8}$ Alterado recentemente pela $\mathrm{L} \mathrm{n}^{\circ}$ 146/99, 01-09. Até 1989, a falta de regulamentação deste tipo contratual conduziu o seu desenvolvimento a "foros de marginalidade", tendo esta preocupação sido denunciada quer pelo Conselho das Comunidades (Resolução nº de 18-12 de 1979), quer pelo Parlamento Europeu.
} 
é de 12 meses (prorrogável até 24 meses), ou de 6 meses, excepto se a celebração do contrato de utilização de trabalho temporário tiver sido justificada por substituição do trabalhador (al. a) do art. $9^{\circ}$ do DL n 358/89, de 17-10) ou necessidades intermitentes de trabalhadores para a prestação de apoio familiar directo (al. g) do art. $9^{\circ}$ do DL n 358/89, de 17-10), situação na qual a duração do contrato não pode exceder a cessação da causa justificativa (n 3 do art. $9^{\circ}$ do DL n 358/89, de 17 $10)$.

Em teoria, as empresas de trabalho temporário devem criar empregos permanentes adicionando tarefas de curto prazo nas diferentes empresas pelo que, de acordo com o $\mathrm{n}^{\circ} 9$ do art. $9^{\circ}$ do supra referido diploma, é proibida a sucessão de trabalhadores temporários no mesmo posto de trabalho quando tenha sido atingida a duração máxima prevista na lei.

Acresce que o trabalho temporário constitui uma forma aliciante de emprego para a empresa utilizadora. A empresa utilizadora "compra” trabalho temporário como compra qualquer outro bem ou serviço. Na medida em que esta está desobrigada das obrigações genéricas que acompanham qualquer contratação e desenvolvimento de uma relação de trabalho (incluindo os custos com a extinção da relação), os custos - salariais e outros - encontram-se significativamente reduzidos, não obstante a mediação das agências de trabalho temporário.

À semelhança do que acontece noutros países da UE, o essencial da regulamentação deste tipo contratual consiste, por um lado, em limitar a duração a fim de evitar que não se substitua ao emprego permanente, e por outro lado, a fixar um mínimo de garantias para os trabalhadores em termos de condições de trabalho e de remuneração (Lestrade, 1999). E tal como o reconhecem estudos realizados pela Fundação Europeia para a Melhoria das Condições de Vida e de Trabalho, o interesse principal no recurso ao trabalho temporário é o de permitir às empresas fazer face às suas necessidades variáveis associando a este o factor de “desresponsabilização contratual” não só da empresa utilizadora, como também da ETT ${ }^{9}$.

\section{Quadro sinopse - Contrato de trabalho temporário}

\begin{tabular}{|c|c|c|}
\hline & $\begin{array}{l}\text { Anterior Lei } \\
\text { - Regime do Decreto-Lei } \\
\mathbf{n}^{\mathbf{0}} \text { 358/89, de } 17-10 \\
\end{array}$ & $\begin{array}{c}\text { Código do Trabalho } \\
\text { - Regime da Lei } n^{\circ} \text { 99/2003, de } \\
27-08 \\
\end{array}$ \\
\hline $\begin{array}{l}\text { Contrato de } \\
\text { trabalho } \\
\text { temporário }\end{array}$ & $\begin{array}{l}\text { Este diploma consagra o } \\
\text { regime legal do trabalho } \\
\text { temporário estabele-cendo } \\
\text { uma relação jurídica } \\
\text { triangular e considerando } \\
\text { três figuras distintas: o } \\
\text { regime do contrato de } \\
\text { utilização de trabalho } \\
\left.\text { temporário (art. } 9^{\circ}-17^{\circ}\right) \text {; o }\end{array}$ & $\begin{array}{l}\text { Mantém, parcialmente, o regime } \\
\text { disposto no DL } \mathrm{n}^{\circ} 358 / 89 \text {, de } \\
17-10 \text { : a redacção dos art. } 1^{\circ} \text { a } \\
25^{\circ} \text { do } 358 / 89 \text {, de } 17-10 \text {, } \\
\text { mantém-se inalterada. } \\
\text { Por seu lado, o regime da } \\
\text { cedência ocasional de } \\
\text { trabalhadores modifica-se e é } \\
\text { incorporado pelo Código (art. }\end{array}$ \\
\hline
\end{tabular}

\footnotetext{
${ }^{9}$ Motivo pelo qual foi por vezes difícil de aceitar numa série de países europeus tais como a Bélgica, a Alemanha, a Itália. Também sobre a precariedade e a importância do trabalho temporário no mercado de trabalho inglês, cfr. Green, F. (2000), “Travail temporaire et precarité de l'emploi en Grande-Bretagne”, in Lestrade, B. e Boutillier, S. (org.), Les Mutations du Travail en Europe, Harmattan, Paris, pp. 263-272.
} 


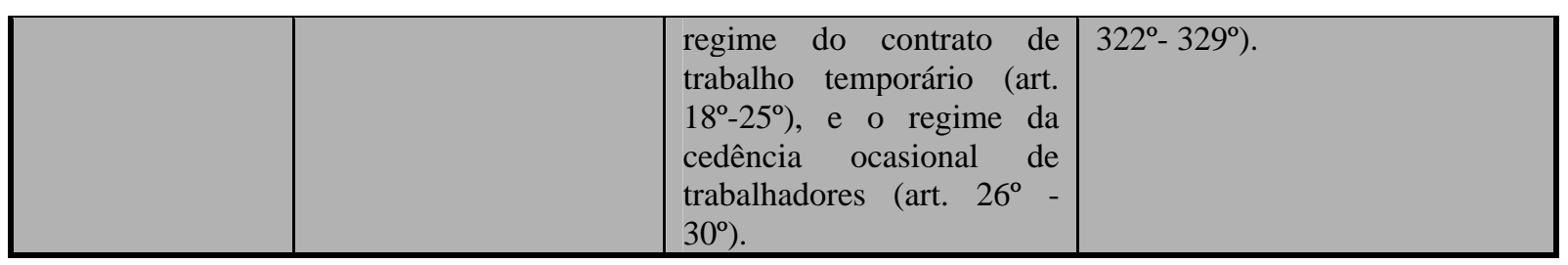

\subsection{O contrato de trabalho a tempo parcial}

Outra forma flexível de trabalho e/ou emprego é a contratação a tempo parcial. A tendência para a flexibilidade registada nos últimos trinta anos fez acentuar a contratação regular de trabalhadores destinados a substituir outros posto de trabalho antes ocupados por empregados em regime de tempo inteiro. Para alguns autores como Redinha, o trabalho a tempo parcial deixou de ser considerado como "modalidade de aproveitamento de uma força de trabalho periférica (Redinha, 1998: 339), ganhando consistência a ideia de que é necessário redistribuir o tempo de trabalho, passando, então, o trabalho a tempo parcial a ser encarado como uma alternativa ou um sucedâneo do emprego a tempo completo".

Como já o afirmámos, e na linha do que propugnam autores como Meda, o trabalho a tempo parcial - para a maioria das empresas - corresponde à vontade de flexibilizar o tempo de trabalho e não de reduzi-lo (Meda, 1997: 35-36 e Rebelo, 2003:104).

Esta forma de contratação aparenta-se, pela natureza do seu vínculo contratual, com o modelo de contratação típico - o trabalho assalariado a tempo inteiro - mas dele difere consideravelmente por duas razões. Em primeiro, porque a duração do trabalho é inferior à duração legal e para a generalidade dos autores, embora não haja uma só definição do trabalho a tempo parcial, trata-se de uma forma de contratação na qual o trabalhador presta um número de horas inferior ao dos trabalhadores a tempo completo ${ }^{10}$. Embora, em termos genéricos, a expressão "trabalho a tempo parcial” seja sempre relativa a uma situação de duração normal legal ou convencional de trabalho, inferior à duração legal "normal”, existem para esta realidade diferentes acepções. Desde logo, o BIT define o trabalho a tempo parcial como uma forma de "emprego assalariado sendo a sua duração sensivelmente mais curta do que a duração normal em vigor em determinada empresa”. Por seu turno, a Convenção da OIT nº 175 (1994) estabelece que a expressão trabalhador a tempo parcial designa qualquer trabalhador cuja prestação tenha uma duração inferior à duração normal da actividade dos trabalhadores a tempo completo numa situação comparável.

\footnotetext{
${ }^{10}$ De realçar que a duração média dos contratos a tempo parcial diverge de país para país (Tremblay, D.G. (1992), "Les tendances de l'emploi: flexibilité et précarité”, in Tremblay e Villeneuve (org.), Travail et société, Agence d' Arc, Montreal).
} 
Em segundo, porque constitui uma forma de contratação excepcional e daí a sua redução a escrito, nela constando expressamente a livre escolha do trabalhador, assim como o período normal de trabalho diário e semanal $\left(\mathrm{n}^{\circ} 1 \text { do art. } 184^{\circ} \mathrm{CT}\right)^{11}$.

A aceitação desta nova forma de trabalho assenta na possibilidade de - mantendo os empregos existentes - permitir a criação de outros. Existem alguns factores preponderantes que motivam a criação de empregos a tempo parcial: por um lado, permite programar o trabalho de forma regular e periódica, aumentando a produtividade e adaptando-se a procuras variáveis e conjunturas diversas; por outro, diminuir os custos com o pessoal (nomeadamente os encargos sociais do trabalho a tempo inteiro e eventuais pagamentos a título de trabalho suplementar); por fim, satisfazer as preferências de alguns trabalhadores que desejem conciliar trabalho e obrigações familiares ou outras (Rebelo, 2001a: 414-415).

A partir dos anos 1980 a contratação a tempo parcial surge fundamentalmente como uma forma de emprego flexível (através da ideia de partilha de emprego), permitindo às empresas um ajustamento rápido às exigências da clientela e apresentando-se simultaneamente como um meio de luta contra o desemprego.

De acordo com alguns autores é possível estabelecer uma tipologia da contratação a tempo parcial distinguindo três categorias de trabalho a tempo parcial: trabalho a tempo parcial provisório, aquele que é visto como uma medida alternativa ao despedimento por motivos económicos ou conjunturais; trabalho a tempo parcial secundário, quando o trabalho a tempo parcial é involuntário e corresponde, a uma actividade indiferenciada e acompanhada de baixos salários; trabalho a tempo parcial atractivo, quando se trata de um emprego criado com a finalidade de aliciar ou manter trabalhadores altamente qualificados (Tilly, 1991: 11 e segs).

A promoção do trabalho a tempo parcial procurou responder a três principais motivações: facilitar a conciliação da vida profissional e da vida privada, flexibilizar o emprego e, por fim, partilhar o emprego. Estudos realizados a nível europeu demonstram que a análise do trabalho a tempo parcial, enquanto modalidade de emprego exige que atentemos na sua caracterização considerando alguns aspectos fundamentais, nomeadamente o sector de actividade económica, a idade, ou o género (Rubery, et. al., 1995). Assim, uma das características gerais do trabalho a tempo parcial é a sua forte feminização (Beechey e Perkins, 1987). Nenhuma outra forma de emprego está a tal ponto sexuada e, de facto, são as mulheres o grupo de trabalhadores com expressão mais significativa ao nível da contratação a tempo parcial (Hoffman e Lapeyre, 1995: 32).

Além disso, a concentração do trabalho a tempo parcial nos sectores de forte impacto feminino evidencia o efeito sectorial desta forma de trabalho. Ao nível sectorial, o trabalho a tempo parcial apresenta-se em certos sectores de actividade como um modo massivo de gestão da mão-deobra: é o caso dos serviços (v.g., da restauração e hotelaria, da limpeza, do comércio e da

\footnotetext{
${ }^{11}$ Não obstante, e apesar de se continuar a exigir forma escrita para a celebração do contrato, o número de dias de trabalho a fixar por acordo não tem de ficar clausulado por escrito ( $\mathrm{n}^{\circ} 3$ do art. $180^{\circ}$ e $\mathrm{n}^{\circ} 3$ do art. $184^{\circ}$ ).
} 
distribuição) onde a prática de tempo parcial está há muito associada às profissões usualmente ocupadas por mulheres (Maruani, 1993 : 135-141).

Tratado de forma incipiente na ex-LDT (nomeadamente no art. $43^{\circ}$ do DL n ${ }^{\circ} 409 / 71$, de 27 09), em Portugal desde o Acordo de Concertação Estratégica, de 1996, que o trabalho a tempo parcial surge como um instrumento da política activa do emprego "desde que voluntário e reversível e quando daí resulte a contratação de novos trabalhadores”. Não obstante, o trabalho a tempo parcial apenas se encontra juridicamente enquadrado a partir de 1999, com a Lei $\mathrm{n}^{0}$ 103/99, de 26-07. Assim, desde essa data - e o actual Código do Trabalho manteve inalterada a noção no seu art. $180^{\circ}$ - que se considera trabalho a tempo parcial, o trabalho prestado que corresponda a "um período normal de trabalho semanal igual ou inferior a $75 \%$ do praticado a tempo completo numa situação comparável”. De acordo com o disposto no art. $182^{\circ}$ CT, as situações são “comparáveis” quando, os trabalhadores no mesmo estabelecimento prestem idêntico tipo de trabalho, devendo ser levadas em conta a antiguidade e a qualificação técnica e profissional.

O trabalho a tempo parcial pode ter um carácter reversível - e tende a funcionar numa perspectiva de gestão provisional do emprego - na medida em que nos termos do art. $186^{\circ} \mathrm{CT}$ (e mantendo a letra do art. $3^{\circ}$ da anterior Lei $\mathrm{n}^{\circ}$ 103/99, de 26-07) um trabalhador a tempo completo pode passar a trabalhar a tempo parcial a título definitivo ou por período determinado que pode ir até 3 anos ( $\mathrm{n}^{\circ} 4$ do art. $186^{\circ} \mathrm{CT}$ ), findos os quais pode o trabalhador retomar a prestação de trabalho a tempo completo.

Por outro lado importa distinguir em matéria de trabalho a tempo parcial, duas variantes: a modalidade optativa (o tempo parcial escolhido) e o tempo parcial involuntário. No primeiro caso, trata-se de uma modalidade de gestão individual do tempo de trabalho por iniciativa do trabalhador; no segundo, trata-se de formas de criação de empregos parciais por iniciativa do empregador e impostas aos trabalhadores.

Além disso - e alterando a redacção da Lei n 103/99, de 26-07 - o Código do Trabalho estabelece preferência na admissão ao trabalho a tempo parcial de um grupo de trabalhadores onde se incluem: trabalhadores com responsabilidades familiares; trabalhadores com capacidade de trabalho reduzida; pessoas com deficiência ou doença crónica e/ou ainda trabalhadores que frequentem estabelecimentos de ensino médio ou superior. Acresce que o trabalhador que pretenda usufruir do regime de reforma parcial, beneficia também da preferência prevista no número anterior (art. $183^{\circ} n^{\circ} 2 \mathrm{CT}$ ).

Concluindo este ponto, podemos reafirmar que o trabalho a tempo parcial faz parte das formas flexíveis de emprego representando, para alguns autores, um elemento de um "movimento global de precarização dos empregos e como contra-fogo à reivindicação da redução do tempo de trabalho” (Meda, 1997: 83), pois é caracterizável não como uma forma de partilha de emprego, mas sim pela definição de um estatuto de emprego (Maruani e Drancourt, 1989 e, ainda, Bertrand, 1991). 


\section{Quadro sinopse - Contrato de trabalho a tempo parcial}

\begin{tabular}{|c|c|c|}
\hline & $\begin{array}{c}\text { Anterior Lei } \\
\text { - Regime da Lei }{ }^{\circ} \\
\text { 103/99, de } 26-07\end{array}$ & $\begin{array}{c}\text { Código do Trabalho } \\
\text { - Regime da Lei } \text { n }^{\circ} \text { 99/2003, de } \\
27-08\end{array}$ \\
\hline $\begin{array}{c}\text { Contrato de } \\
\text { trabalho a } \\
\text { tempo parcial }\end{array}$ & $\begin{array}{l}\text { Contempla-se a referência } \\
\text { a um período semanal igual } \\
\text { ou inferior a } 75 \% \text { do tempo } \\
\text { completo }\left(\mathrm{n}^{\circ} 1 \text { do art. } 1^{\circ}\right) \text {. } \\
\text { Exige-se forma escrita para } \\
\text { a celebração do contrato } \\
\text { nele devendo constar } \\
\text { expressamente o horário de } \\
\text { trabalho semanal e diário } \\
\left(\mathrm{n}^{\circ} 5 \text { do art. } 1^{\circ}\right) \text {. }\end{array}$ & $\begin{array}{l}\text { Mantém-se a referência a um } \\
\text { período semanal igual ou } \\
\text { inferior a } 75 \% \text { do tempo } \\
\text { completo }\left(\mathrm{n}^{\circ} 1 \text { do art. } 180^{\circ}\right) \text {. } \\
\text { Exige-se forma escrita para a } \\
\text { celebração do contrato. Contudo } \\
\text { o número de dias de trabalho } \\
\text { deve ser fixado por acordo mas } \\
\text { não tem de ficar clausulado por } \\
\text { escrito }\left(\mathrm{n}^{\circ} 3 \text { do art. } 180^{\circ} \text { e } \mathrm{n}^{\circ} 3\right. \\
\left.\text { do art. } 184^{\circ}\right) \text {. }\end{array}$ \\
\hline
\end{tabular}

\section{4. $O$ contrato de teletrabalho}

Com o desenvolvimento da informática e da miniaturização dos equipamentos, o "teletrabalho" constitui hoje um modo de organização que oferece grande flexibilidade aos empregadores, representando uma vantagem concorrencial importante. As empresas têm a possibilidade de optar pelo trabalho à distância e de fraccionar esta forma de trabalho como entendam.

No seio dos países da UE importa considerar a diversidade de conceitos que envolvem o enquadramento desta figura (Comissão Europeia, 1996).

Desde logo é preciso realçar que ao teletrabalho correspondem práticas muito diversas, que podemos agrupar em quatro grupos: o trabalho em telelocal, ou seja, a actividade desenvolvida num centro equipado informaticamente onde assalariados de várias empresas exercem actividade; o teletrabalho em equipa, quer seja trabalho descentralizado ou não; o "teletrabalho no domicílio", de acordo com o qual o assalariado trabalha no seu domicílio, utilizando material informático (esta forma aproxima-se do trabalho no domicílio tradicional); o teletrabalho à la carte $^{12}$, onde o trabalhador trabalha no domicílio, na empresa ou junto do cliente, exercendo a sua actividade de forma irregular durante um ou dois dias por semana (Rebelo, 2003: 125).

Considerando esta tipologia, importa igualmente clarificar - no plano do seu enquadramento jurídico - as relações entre trabalho subordinado e trabalho independente no âmbito do teletrabalho.

\footnotetext{
${ }^{12}$ Esta forma de trabalho é geralmente o resultado de um acordo mais ou menos formal entre a empresa e um assalariado ou grupo de assalariados (na sua maioria trabalhadores qualificados ou muito qualificados) para que aqueles possam exercer uma parte da sua actividade, um ou dois dias por semana no seu domicílio. Esta forma de trabalho encontra-se muito desenvolvida nos EUA, onde diversas empresas (v.g., ATT) propõem sistematicamente, no momento do recrutamento, possibilidades de teletrabalho aos seus quadros.
} 
Até à aprovação do Código do Trabalho - que consagrou expressamente o regime jurídico do teletrabalho em Portugal - o teletrabalho não constituía propriamente uma categoria legal. Até essa altura a definição do teletrabalhador passava pela simples consideração de saber se o trabalhador - trabalhando à distância do local onde o empregador tem a sua actividade dominante e mediante o recurso às TIC - executava a sua prestação sujeito aos indícios de subordinação jurídica, ou se se tratava de um trabalhador autónomo. Para efeitos do Código "considera-se teletrabalho a prestação laboral realizada com subordinação jurídica habitualmente fora da empresa do empregador e através do recurso a tecnologias de informação e comunicação” (art. 233 CT).

Quer a nível organizacional, quer a nível jurídico, as questões que se colocam são as seguintes: o teletrabalho é uma nova forma de trabalho?; constituirá o teletrabalhador uma nova categoria de trabalhador?

Enquanto modo de organização do trabalho, o teletrabalho representa algo de verdadeiramente novo - embora em numerosos domínios exista há já alguns anos, tendo beneficiado de numerosas evoluções e progressos técnicos conjugados que lhe conferem agora uma nova envolvente - pois como observa Redinha "o teletrabalho (...) é também uma nova forma de viver, uma vez que são afectadas as necessárias deslocações de e para o trabalho, a separação entre tempo de trabalho e lazer, a coincidência entre o local de trabalho e de residência, etc” (Redinha, 1999: 88).

Se bem que o teletrabalho continue a representar uma forma de trabalho com tendência crescente, permanece pouco conhecido, não obstante alguns estudos que lhe foram consagrados (Schneider e Rosensohn, 1997: 21-24). O grande número de dispersão de definições e de dados neste domínio, faz com que seja difícil afirmar com precisão quem pode ser qualificado como teletrabalhador e/ou quantos teletrabalhadores há actualmente.

Desde logo, e muito embora a sua noção tenha já sido fixada nalguns ordenamentos jurídicos (incluindo o português) - dada a recenticidade do fenómeno - ainda não existe um consenso acerca da sua definição jurídica junto da doutrina. Se alguns autores são generalistas quando propõem uma noção, considerando que se trate de um forma de organizar e executar trabalho à distância, outros como Blanpain propõem uma noção funcional do teletrabalho: trabalho executado por uma pessoa (trabalhador subordinado, trabalhador independente) cuja actividade é exercida em larga medida num lugar que não o local tradicional, para o empregador ou um cliente, e que recorre a tecnologias de ponta (Blanpain, 1994: 45).

Para nós, o teletrabalho é uma forma de actividade executada em local exterior à empresa empregadora à qual o trabalhador está vinculado, quer como trabalhador dependente, quer como trabalhador independente. O local de trabalho pode ser o seu domicílio pessoal ou um local cedido pelo(s) empregadore(s) e equipado com todo o material informático e telemático necessário à execução do trabalho à distância (Rebelo, 2003: 130). Assim, o teletrabalho comporta vários aspectos e compreende formas muito distintas de trabalho; trata-se, então, de uma forma de trabalho multidimensional. 
O progresso técnico proporcionado pela utilização remota das novas tecnologias permite deslocalizar o trabalho para o domicílio dos trabalhadores ou para telecentros (centros polivalentes de trabalho), envolvendo a dispersão física dos empregados do local central de trabalho para locais distantes, onde estes trabalhadores são contratados mediante contratos de trabalho muito variados (v.g., por tempo indeterminado ou por tempo determinado; a tempo inteiro ou a tempo parcial, etc). Mas, como realça Moniz "as dificuldades de gestão e de supervisão de uma rede de teletrabalho, não diz respeito apenas ao teletrabalho, mas sobretudo diz respeito a novas modalidades de organização do trabalho e de organização empresarial” (Moniz, 1998: 61).

Mas o teletrabalho apresenta também alguns inconvenientes que importa reter: para o teletrabalho subordinado (por conta de outrem) uma das desvantagens que pode ocorrer é a de uma efectiva "sobrecarga de horário de trabalho“, cuja fiscalização nesta modalidade se torna especialmente difícil (Rebelo, 2003: 133). Assim, o teletrabalho limita o tempo e o lugar de supervisão, desenhando uma nova atitude nas relações entre empregador e subordinado: a supervisão de teletrabalhadores como forma de gestão do trabalho leva à necessidade de "monitorização" dos resultados.

Uma outra desvantagem é a da quase inevitável sobreposição entre a vida profissional e a vida privada do teletrabalhador.

Ao contrário das outras formas de trabalho aqui anteriormente mencionadas, nos países da UE 15 a legislação laboral para os teletrabalhadores que permite regular adequadamente as relações entre teletrabalhadores e empregadores é muito recente. Até há pouco tempo - pelo menos até à assinatura do Acordo Quadro sobre Teletrabalho em Julho de 2002 - a generalidade das situações de teletrabalho, pelo menos para os trabalhadores subordinados, estão cobertas pelos regimes nacionais do trabalho no domicílio.

Com a emergência do Código do Trabalho - e a inclusão de um regime jurídico específico para o teletrabalho subordinado - ficam de iure resolvidas algumas questões, nomeadamente no que respeita ao estatuto jurídico do teletrabalhador, às suas condições de trabalho (que têm que ver, nomeadamente, com a inevitável confusão entre a vida profissional e a vida privada), à igualdade de tratamento e, ainda, à resolução de problemas transfronteiriços.

No que concerne ao estatuto jurídico do teletrabalhador, por exemplo, presume-se hoje um estatuto de trabalhador subordinado (com as consequentes implicações jurídicas) e, se até aqui muitos teletrabalhadores tinham problemas de protecção social - nos casos de doença, maternidade e/ou reformas e nas situações de desemprego -, hoje a tutela social no caso do teletrabalho subordinado encontra-se plenamente consagrada (v.g., no que respeita à segurança, higiene e saúde no trabalho o disposto no art. $239^{\circ} \mathrm{CT}$ ). Por outro lado, e tratando-se de teletrabalho subordinado, o Código do trabalho estatui que o fornecimento dos instrumentos de trabalho adequados à execução pretendida é uma atribuição do empregador e é uma consequência do facto de a aplicação da força de 
trabalho requerer o uso de meios de produção que, embora não pertençam ao trabalhador, lhe ficam confiados (art. $\left.238^{\circ} \mathrm{CT}\right)^{13}$.

Outra importante questão que é contemplada no Código do Trabalho respeita às questões da privacidade e da confidencialidade das informações tratadas no exercício da actividade de teletrabalho subordinado. Importa considerar que o Código do Trabalho consagra expressamente - e em termos genéricos para as formas de trabalho subordinado - a reserva da intimidade (art. $16^{\circ} \mathrm{CT}$ ), a protecção de dados pessoais (art. $17^{\circ} \mathrm{CT}$ ), a reserva e confidencialidade de mensagens enviadas através do correio electrónico (art. $21^{\circ} \mathrm{CT}$ ) e, em especial no que respeita ao teletrabalho, o dever de segredo profissional ( $\mathrm{n}^{\circ} 3$ do art. $242^{\circ} \mathrm{CT}$ ). Além disso, prevê especificamente para a figura do teletrabalho subordinado, a tutela da privacidade no trabalho (art. $237^{\circ} \mathrm{CT}$ ). Assim, o empregador está obrigado a respeitar a privacidade dos teletrabalhadores bem como a proporcionar-lhe boas condições de trabalho, tanto do ponto de vista físico como moral.

Não obstante as disposições agora consagradas no Código do Trabalho, é ao nível das dificuldades na efectiva fiscalização das condições de trabalho por parte das entidades com competência para tal - sobretudo no caso do teletrabalho no domicílio - que esta forma de trabalho parece levantar mais dúvidas.

Se na generalidade dos países da UE a lei tutela o direito à vida privada, colocam-se então vários problemas jurídicos: como podem os empregadores fazer respeitar, por exemplo, as normas de higiene, saúde e segurança num local de trabalho que pode ser simultaneamente o domicílio do trabalhador; ou como podem as instâncias de controlo fiscalizar as condições de trabalho no domicílio dos assalariados (nomeadamente, o respeito das normas de saúde e de segurança; os riscos de locais de trabalho inadequados ou os riscos ligados ao trabalho isolado) (Rebelo, 2004).

Como já referimos precedentemente, o controlo destes aspectos é difícil em razão da inviolabilidade do domicílio, razão pela qual é preciso reflectir sobre as novas exigências de mecanismos de controlo das condições do exercício do teletrabalho subordinado.

\section{Quadro sinopse - Contrato de teletrabalho}

\begin{tabular}{|c|l|l|l|}
\hline & & Anterior Lei & \multicolumn{1}{c|}{$\begin{array}{c}\text { Código do Trabalho } \\
\text { - Regime da Lei no 99/2003, de } \\
\text { 27-08 }\end{array}$} \\
\hline $\begin{array}{l}\text { Contrato de } \\
\text { teletrabalho }\end{array}$ & & $\begin{array}{l}\text { Ausência de regime } \\
\text { jurídico. }\end{array}$ & $\begin{array}{l}\text { Forma de trabalho subordinado } \\
\text { onde existe vínculo de } \\
\text { subordinação jurídica (art. } \\
233^{\circ} \text { ). } \\
\text { Contrato sujeito a forma escrita } \\
\text { (art. 234 } \mathrm{n}^{\circ} \text { 2) } \\
\text { Um trabalhador sujeito a um }\end{array}$ \\
\hline
\end{tabular}

${ }^{13}$ A posse destes instrumentos por parte do trabalhador depende, por conseguinte, da natureza do trabalho, do grau de exclusividade do uso do instrumento ou da máquina e dos usos profissionais. A violação do dever de guarda, além de poder obrigar o trabalhador a indemnizar, constitui ainda infracção disciplinar que pode conduzir, no limite (por lesão de interesses sérios da empresa) ao despedimento com justa causa (al. e) do n 3 do art. $396^{\circ} \mathrm{CT}$ ). 


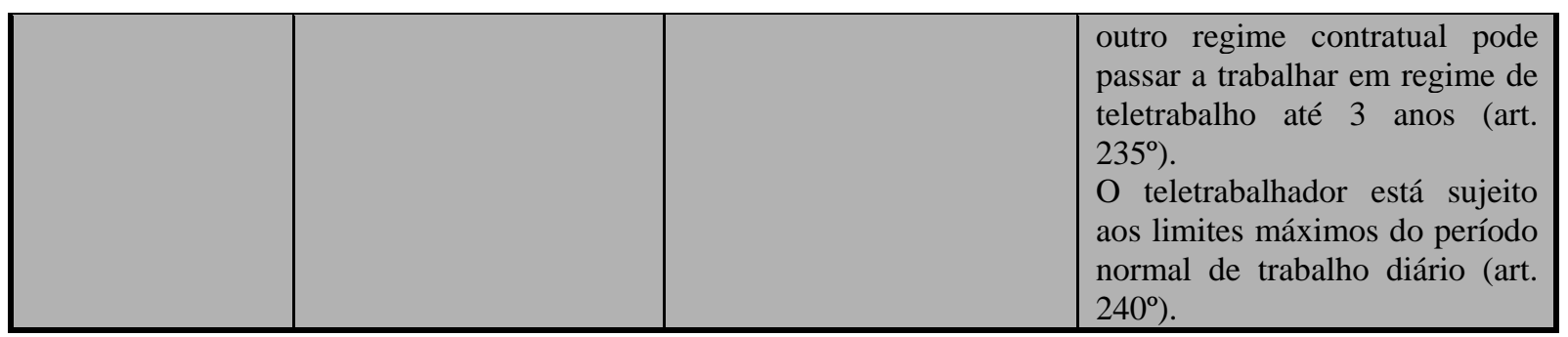

\section{3. $O$ contrato de prestação de serviços e o trabalho independente}

Paralelamente às formas de trabalho subordinado - cuja tutela se inclui no âmbito do objecto normativo do Direito do Trabalho - é importante reconhecer que outras formas de trabalho permanecem actualmente marginais em relação à massa dos assalariados.

A definição de trabalho independente em Portugal é vaga e encontra-se dispersa por diversas fontes.

De acordo com o INE (Instituto Nacional de Estatística) a "estrutura do emprego por profissão" é dividida em quatro categorias/grupos de indivíduos: "os trabalhadores por conta de outrem”, “os trabalhadores por conta própria empregadores”, “os trabalhadores por conta própria isolados” e, ainda, “os trabalhadores familiares não remunerados”.

De acordo com a lei, se tivermos em consideração que a lei do trabalho cobre as situações de trabalho subordinado juridicamente, temos então de considerar que, a contrario, os trabalhadores por conta própria (isolados e/ou empregadores) representam uma importante categoria de trabalhadores em relação aos quais se encontra subtraída a tutela juslaboral (e inerente conteúdo normativo e obrigacional de tutela social).

Neste sentido importa referir aqui um outro tipo de contratação laboral: a contratação celebrada mediante contratos de prestação de serviços. A lei portuguesa considera que o trabalhador está vinculado para com a outra parte por um contrato de prestação de serviços, quando "uma das partes se obriga a proporcionar à outra certo resultado do seu trabalho intelectual ou manual, com ou sem retribuição" (art. $1154^{\circ}$ do Código Civil). Este contrato, nas suas diversas modalidades (designadamente, o mandato e a empreitada), constitui a principal forma jurídica através da qual se desenvolve a prestação de trabalho autónomo. 
Contudo, actualmente num contexto de precarização das formas de trabalho importa reflectir sobre o denominado "falso trabalho independente". Sabendo-se que esta noção cobre realidades muito diversas, a questão que se coloca é a de saber se estamos perante uma nova categoria de trabalhadores independentes. Atente-se, por exemplo, na estratégia de externalizar certos postos de trabalho propondo-se aos assalariados da empresa que ocupam estes postos que se tornem prestadores de serviços para assegurar o funcionamento da empresa.

Assim, em diversos países europeus expressam-se hoje duas tendências contrárias sobre "as fronteiras do trabalho assalariado" (Supiot, 1999: 41). A primeira consiste em reduzir o campo de aplicação do Direito do Trabalho, em benefício de uma concepção estrita do critério de subordinação jurídica. Esta tendência é corolário das políticas legislativas e jurisprudenciais conduzidas para abrir um espaço mais amplo ao trabalho independente. A segunda tendência consiste, pelo contrário, em alargar o campo de aplicação do Direito do Trabalho, recorrendo a outros critérios para além do da subordinação jurídica.

Neste sentido, duas vias são hoje exploradas, dando lugar a inéditas proposições doutrinais e/ou legislativas.

\section{Flexibilidade e mobilidade}

Em ambiente de crescente competitividade empresarial, têm-se exigido ao Direito do Trabalho - que apresenta por excelência uma vocação normativa procurando conciliar quer interesses económicos (ligados ao empregador-empresário), quer interesses sociais (ligados aos trabalhadores) - respostas urgentes em nome da manutenção de "um são relacionamento com o Emprego” (Almeida, P. P. e Rebelo, G, 2004b: 186).

Ora - e porque é fundamental perceber que, mesmo firmando um contrato de trabalho assente numa relação contratual duradoura, as partes se têm hoje de adaptar a um quadro de constante mudança económico-organizacional e de "crescente expectativa mútua” (Lobo Xavier, 1998: 107) - uma das respostas mais interessantes que o normativo laboral oferece em matéria de flexibilidade é justamente, a de permitir o exercício da mobilidade dos recursos humanos.

Em presença de um projecto de mudança na organização do trabalho, há diversas formas de conceber as suas consequências sobre o volume do emprego e "uma delas é adoptar uma postura de alternativa às medidas de flexibilidade quantitativa, que actuam ao nível do 'emagrecimento' organizacional” (Almeida e Rebelo, 2004b: 195).

Em termos gerais importa frisar que a ideia de mobilidade (seja de carácter funcional ou de carácter geográfico) suscita, frequentemente, resistências humanas mas também jurídicas (Daugareilh, 1996). Mas, na verdade as empresas tendem a gerir os seus recursos humanos com 
muito mais mobilidade do que aquela que está consagrada na lei, procurando um nível elevado de mobilidade organizacional dos seus trabalhadores.

E, embora alguns autores considerem que a mobilidade funcional amplifica o desequilíbrio contratual entre o empregador e o trabalhador, "a mobilidade funcional assume, na actualidade, extrema importância para a competitividade empresarial: se para os empregadores pode significar a possibilidade de dar respostas atempadas a solicitações (previstas ou imprevistas) de clientes cada vez mais exigentes, para os trabalhadores significa - e tendencialmente cada vez mais - uma condição simultânea de acesso ao mercado de trabalho e de manutenção de emprego" (Almeida e Rebelo, 2004b: 214).

No plano jurídico duas vias têm sido adoptadas para promover as mobilidades -internas e externas - nas empresas ${ }^{14}$ : criação de normas destinadas ao conjunto dos trabalhadores (contidas, por exemplo, em regulamentos internos de empresa ou em convenções colectivas de trabalho) ou inclusão de cláusulas contratuais de mobilidade nos contratos individuais de trabalho (Almeida e Rebelo, 2004b: 214).

Ora importa sublinhar em particular a importância do conceito de mobilidade funcional. Desde logo, é preciso referir que o Direito do Trabalho associa o conceito de mobilidade funcional aos poderes tradicionais do empregador: pela celebração do contrato individual de trabalho o empregador detém um poder de autoridade e direcção legalmente reconhecido (art. $10^{\circ} \mathrm{CT}$ ). E, como refere Monteiro Fernandes, não se deve considerar que o trabalhador se encontra "encerrado no casulo da sua 'categoria', entregue à repetição continuada do correspondente padrão de actividade” (Monteiro Fernandes, 2004: 207), estando também sujeito à iniciativa do empregador para poder alargar ou diversificar a sua actividade de trabalho. Na linha de anterior legislação também o Código do Trabalho consagra a figura da mobilidade ampliando o seu conteúdo, a partir da reconfiguração do objecto de trabalho, que é agora a actividade. E nos termos do disposto no $\mathrm{n}^{\circ} 1$ do art. $314^{\circ}$ do Código do Trabalho estabelece que "o empregador pode (...) encarregar temporariamente o trabalhador de funções não compreendidas na actividade contratada (...)”.

E este instrumento de flexibilidade - a mobilidade funcional - poderá ser fundamental para assegurar a muitas empresas a tal "sobrecapacidades para fazer face a um imprevisto" sem recorrer a medidas de flexibilidade defensiva.

\footnotetext{
${ }^{14}$ Entendendo aqui a distinção entre mobilidade interna, ou seja a possibilidade de transferência dentro das empresas ou entre empresas que compõem o respectivo grupo, e "mobilidade externa" que traduz a possibilidade de mudança entre empresas diferentes.
} 


\section{Considerações finais}

Como reafirmámos atrás, no sentido de "aumentar a competitividade da economia e das empresas” (de acordo com a exposição de motivos), o actual Código do Trabalho vem reforçar o movimento de flexibilização da lei laboral. Este movimento de flexibilização da lei do trabalho que teve na sua motivação a criação de condições "com vista a facilitar a adaptação aos desafios colocados pela globalização” (exposição de motivos), não pode - nem deve - ser entendida sem a compreensão global dos desafios socio-económicos a que Portugal se encontra sujeito.

Considerando o movimento de deslocalização do trabalho - que parece imparável e se traduz na fuga de postos de trabalho para os países onde os salários são muito baixos - que se repercute também em Portugal e traz consigo encerramentos de empresas e perdas de postos de trabalho que podem (e devem) ser compensados pela criação de postos noutros sectores, é preciso salvaguardar a competitividade das empresas e o funcionamento da generalidade do sistema de emprego português.

Assim, para nós, o problema fundamental que hoje se coloca ao nível do mercado de trabalho e emprego é o de saber como conciliar a implementação da flexibilidade na organização do trabalho, imprescindível para a competitividade económica das empresas, com um nível mínimo de precariedade laboral.

Representando as diversas formas de contratação paralelas à contratação por tempo indeterminado (sem termo) um instrumento de gestão flexível, é preciso que os empresários/empregadores vejam nas actuais propostas de flexibilização do Código do Trabalho um meio de articular flexibilidade da gestão com a ideia de qualificação dos recursos humanos.

Perante a consagração destas propostas legais, as empresas terão numerosos meios para desenvolver a sua flexibilidade. Se considerarmos que a empresa flexível é aquela que dispõe de sobrecapacidades - ligadas não só aos produtos e aos processos mas, maxime, às organizações e às pessoas - para fazer face a um imprevisto, é preciso que as empresas/empregadoras compreendam que a sua capacidade de adaptação a mudanças não antecipadas passa por uma acção de planeamento estratégico e antecipado da gestão das pessoas. 
A questão que se coloca será então a seguinte: será preferível enveredar por medidas de flexibilidade tendencialmente não qualificantes assentes numa óptica de gestão a curto prazo - como por exemplo a contratação determinada a curto prazo que não promove a qualificação e conduz, inevitavelmente, quer à instabilidade do percurso profissional dos trabalhadores, quer à instabilidade da própria gestão empresarial - ou, em alternativa, por medidas de flexibilidade tendencialmente qualificantes baseadas em políticas de gestão a longo prazo - que, por exemplo, apoiadas na ideia de mobilidade profissional, permitam assegurar a formação dos trabalhadores (e o enriquecimento das suas competências), conferindo, paralelamente, estabilidade quer ao percurso profissional dos trabalhadores, quer à própria gestão empresarial?

No que se refere a este grupo de medidas de flexibilidade tendencialmente qualificantes o legislador reforçou, em geral, as regras acerca da mobilidade profissional (mobilidade funcional e mobilidade geográfica) e, em particular, acerca do conceito de mobilidade funcional. Ora, a efectiva promoção desta medida de flexibilidade só será viável (em termos de concretização) se estiver apoiada numa óptica de estabilidade contratual e de acesso à formação contínua.

A partir da proposta globalmente flexibilizante do Código do Trabalho caberá às partes envolvidas na contratação (ao nível individual, empregador e trabalhador e, ao nível colectivo, os parceiros sociais) avaliar as alternativas em jogo. E se o actual sistema juslaboral denota uma evolução globalmente flexibilizante, julgamos fundamental advogar uma mudança de atitude social com vista à adopção prevalente de medidas de flexibilidade qualitativa que, assegurando a adequada tutela e dignidade (pessoal e social) dos trabalhadores, permitam simultaneamente, aumentar a competitividade empresarial.

De realçar que a competitividade económica e/ou empresarial não é incompatível com uma visão a longo prazo onde tem lugar a flexibilidade qualitativa e qualificante dos recursos humanos. Pelo contrário: é da valorização dos recursos humanos que depende a preservação do mercado de trabalho português. E precisamente porque partilhamos da ideia de que a negociação colectiva é uma condição essencial para o sucesso de um movimento de flexibilização normativa do trabalho, advogamos também que é essencial que esta seja dinamizada em todos os sectores da actividade económica. 


\section{Bibliografia}

Almeida, P. P. e Rebelo, G. (2004a), "Desenvolvimento profissional e políticas de Gestão de Recursos Humanos: medidas de flexibilidade qualificantes e formação”, Inofor, Lisboa.

Almeida, P. P. e Rebelo, G. (2004b), A Era da Competência - Um novo paradigma para a Gestão de Recursos Humanos e o Direito do Trabalho, RH Editora, Lisboa.

Barker, K. e Christensen, K. (ed.) (1998), Contingent Work - American Employment Relations in Transition, IRL Press, Ithaca.

Beechey, V. e Perkins, T. (1987), A Matter of Hours: Women, Part-time Work and the Labour Market, Polity, Cambridge.

Bertrand, O. (1991), “Les systemes d'emploi tertiaires”, in Gadrey, J. e Gadrey, N. (dir.), La gestion des ressources humaines dans les services et le commerce, L’Harmattan, Paris, pp.117-137.

Blanpain, R. (dir.) (1994), Employment security law and practice in Belgium, Bulgaria, France, Germany, Great-Britain, Italy, Japan and the European Communities, Leuven Peters Press, Lovaina.

Clauwaert, S. (1999), Survey of Legislation on Temporary Agency Work, European Trade Union Institute, Bruxelas.

Comissão Europeia (1996), Telework 1994/95 Programme, Commission of the European Communities, Bruxelas.

Eurostat (2003), Labour Force Survey - Principal Results 2002, Statistics in Focus, 15/2003. 
Felstead, A. e Jewson, N. (1999), In Work, At home: Towards an Understanding of Homeworking, Routledge, Londres.

Fundação Europeia para a Melhoria das Condições de Vida e de Trabalho (1997), Emprego precário e condições de trabalho na UE, Fundação Europeia para a Melhoria das Condições de Vida e de Trabalho, Dublim.

Godinot, X. e Richou, S. (2003), "La pauvreté en Europe: essai de prospective: quatre scénarios sur la précarité et la grande pauvreté en Europe à l'horizon 2015, Revue Futuribles, 290, pp. 33-48.

Green, F. (2000), “Travail temporaire et precarité de l’emploi en Grande-Bretagne”, in Lestrade, B. e Boutillier, S. (org.), Les Mutations du Travail en Europe, Harmattan, Paris, pp.263-273.

Harvey, M. (1999), "Economies of Time: A Framework for Analysing the Restructuring of Employment Relations”, in Felstead, A. e Jewson, N. (ed.), Global Trends in Flexible Labour, Macmillan, Londres, pp. 27-28.

Hoffman, R. e Lapeyre, J. (dir.) (1995), Le Temps de Travail en Europe - Organisation et réduction, Syros, Paris.

Huuhtanen, P. (1997), The Health and Safety Issues for Teleworkers in the European Union, Rapport de synthése de Pekka Huuhtanen, WP/97/29/EN, Helsinquia.

Lesmele, R. M. e Marot, J. C. (1994), Le Télétravail, Presses Universitaires de France, Paris.

Lestrade, B. (1999), Travail Temporaire: La Fin de L'exception Allemande?, L'Harmattan, Paris.

Lestrade, B. e Boutillier, S. (org.) (2000), Les Mutations du Travail en Europe, Harmattan, Paris.

Lobo Xavier, B.G. (1999), Iniciação ao Direito do Trabalho, Verbo, Lisboa.

Maruani, M. (1993), “Les effets pervers du travail à temps partiel”, in L'emploi des femmes, La Documentation Française, Paris, pp. 135-141.

Maruani, M. e Drancourt, C. N. (1989), La flexibilité à temps partiel, La Documentation Française, Paris. 
Meda, D. (1997), Le partage du travail, La Documentation Française, Paris.

Moniz, A. B. (1998),“Políticas de Emprego e Sociedade da Informação: para uma sociedade do conhecimento", Sociedade e Trabalho, n 2.

Monteiro Fernandes, A. (2002), Um Rumo para as Leis Laborais, Almedina, Coimbra.

OECD Observer (2003), Economic Survey of Portugal, Policy Brief, January.

Pinto, M., et al (1996), Glossário de Direito do Trabalho e Relações Industriais, Serviço das Publicações Oficiais das Comunidades Europeias, Universidade Católica Editora.

Rebelo, G. (2001a), “A flexibilidade no trabalho: as questões da redução do tempo de trabalho e do trabalho a tempo parcial”, Organizações e Trabalho, 26, pp. 31-40.

Rebelo, G. (2001b), "Flexibilidade ou precariedade? Alguns exemplos de formas de trabalho/emprego no contexto europeu”, Actas do IX Encontro da APSIOT, Cd-rom, Celta.

Rebelo, G. (2002a), Emprego e Formas de Precariedade da Actividade Laboral - O Caso de Portugal no Contexto da UE, tese de doutoramento, ISEG/UTL, Lisboa.

Rebelo, G. (2002b), “Para uma tipologia da precariedade da actividade laboral”, Organizações e Trabalho, 28, pp. 69-85.

Rebelo, G. (2002c), “As virtudes da flexibilidade estratégica e ofensiva”, RH Magazine, 22, Setembro de 2002, pp. 20-23.

Rebelo, G. (2003), Emprego e Contratação Laboral em Portugal - Uma Análise Sócio-económica e Jurídica, RHEditora, Lisboa.

Redinha, M. R. G. (1998), “A precariedade do emprego - uma interpelação ao Direito do Trabalho”, in Direito do Trabalho - $I^{\circ}$ Congresso Nacional de Direito do Trabalho, Livraria Almedina, Coimbra, pp. 327-344.

Redinha, M. R. G. (1999), “O teletrabalho”, in Direito do Trabalho - II Congresso Nacional de Direito do Trabalho, Livraria Almedina, Coimbra, pp. 83-102. 
Rubery, J., et. al. (1995), “Changing Patterns of Work and Working-Time in the European Union and the Impact of Gender Division”, in Report for the Equal Opportunities Unit, European Commision, Bruxelas.

Rudolph, H. (2000),“La normalisation de l'emploi atypique? Une discussion sur la dérégulation en Allemagne”, in Lestrade, B. e Boutillier, S. (org.), Les mutations du travail en Europe, Harmattan, Paris, pp. 233-252.

Schneider, B. e Rosensohn, N. (1997), Télétravail, realité ou espérance?, Presses Universitaires de France, Paris.

Supiot, A. (1999), Au-delà de l'emploi. Transformations du travail et devenir du droit du travail en Europe, Flammarion, Paris.

Tilly, C. (1991), "Reasons for the continuing growth of part-time employment”, Monthly Labor Review, vol. CXIV, nº 3, pp. 11.

Tremblay, D.G. (1992), "Les tendances de l'emploi: flexibilité et précarité”, in Tremblay e Villeneuve (org.), Travail et société, Agence d’Arc, Montreal. 